\title{
Platelet Adenylyl Cyclase Activity as a Trait Marker of Alcohol Dependence
}

\author{
John A. Menninger, Anna E. Barón, Katherine M. Conigrave, John B. Whitfield, John B. Saunders, Anders Helander, \\ C. J. Peter Eriksson, Bridget Grant, Paula L. Hoffman, Boris Tabakoff, \\ on behalf of the WHO/ISBRA Collaborative Study Investigators
}

\begin{abstract}
Background: There is compelling evidence that genetic factors play a major role in the development of alcohol dependence. Platelet adenylyl cyclase (AC) activity has been proposed as a biochemical marker for differentiating alcohol-dependent and nondependent subjects, but the sensitivity and specificity of this marker have not been ascertained. The objective of this study was to determine the sensitivity and specificity of platelet AC activity in identifying alcohol-dependent subjects and to ascertain the effect of medical/ psychiatric variables, drinking and smoking history, and age and body weight on AC activity.

Methods: The cross-sectional study was conducted from 1995 to 1998. Participants were 210 Australian White men who were community volunteers and alcohol treatment inpatients in Sydney, Australia. There were 41 nondrinkers, 140 drinkers, and 29 men who were entering alcohol treatment. The main outcome measure was platelet AC activity. Classification variables were plasma ethanol, $\gamma$-glutamyltransferase, aspartate aminotransferase, serum carbohydrate-deficient transferrin (CDT), and urinary 5-hydroxytryptophol/5-hydroxyindoleacetic acid (5-HTOL/5-HIAA) levels, and World Health Organization/International Society for Biomedical Research on Alcoholism Interview Schedule variables, which included alcohol use and dependence criteria.

Results: Among subjects who reported abstinence for at least 4 days, both cesium fluoride (CsF)- and forskolin-stimulated platelet AC activities were significantly lower in those with a lifetime history of alcohol dependence compared with those with no such history ( $p<0.005$ and $p<0.05$, respectively). The sensitivity and specificity of CsF-stimulated AC activity to discriminate individuals with a lifetime history of alcohol dependence were $75 \%$ and $79 \%$, respectively. Similar values for sensitivity and specificity for CsFstimulated AC activity were calculated when discriminating current alcohol dependence in the subjects in our sample. Irrespective of the history of alcohol dependence, persons who had consumed alcohol recently (within the last 3-4 days) showed significantly higher mean basal, CsF-stimulated, and forskolin-stimulated AC activity $(p<0.001)$, as did those who had elevated 5-HTOL/5-HIAA ratios or CDT levels, indicative of recent (heavy) drinking. The "normalization" of platelet AC activity to baseline levels after an individual stops drinking may be related to the generation of new platelets during the abstinence period. Conduct disorder and antisocial personality disorder were not associated with low AC activity, but low forskolinstimulated AC activity was associated with major depression.

Conclusions: We found that CsF- and forskolin-stimulated platelet AC activity discriminates between subjects with and without alcohol dependence in a population of subjects who had not consumed significant quantities of ethanol recently. Recent alcohol consumption is a confounding variable that can alter the measured levels of AC activity. Forskolin-stimulated platelet AC activity also may be influenced by a history of major depression.
\end{abstract}

Key Words: Platelet, Adenylyl Cyclase, Alcohol Dependence, Abstinence, Markers.

$\mathbf{A}^{1}$ LTHOUGH THE DIAGNOSIS of alcohol dependence is widely accepted to reflect a heterogeneous disorder, genetic influences have been shown to play a

From the Departments of Psychiatry (J.A.M.), Preventive Medicine and Biometrics (A.E.B.), and Pharmacology (P.L.H. and B.T.), University of Colorado Health Sciences Center, Denver, Colorado; the Departments of Drug and Alcohol (K.M.C.), Biochemistry (J.B.W.), and Psychological Medicine (J.B.S.), Royal Prince Alfred Hospital and University of Sydney, Sydney, Australia; Department of Mental Health and Alcohol Research (C.J.P.E.), National Public Health Institute, Helsinki, Finland; Division of Biometry and Epidemiology (B.G.), National Institute on Alcohol Abuse and Alcoholism, Rockville, Maryland; and Department of Clinical Neuroscience (A.H.), Alcohol \& Drug Dependence Unit, Karolinska Institutet, Stockholm, Sweden. significant role in the development of alcoholism. A number of markers for the predisposition or vulnerability to

Received for publication December 16, 1999; accepted March 20, 2000.

Financial support was provided by the Banbury Foundation, the National Institute on Alcohol Abuse and Alcoholism, and the World Health Organization/International Society for Biomedical Research on Alcoholism. The Australian data collection was funded by the National Health and Medical Research Council of Australia and the Royal Prince Alfred Hospital Research Foundation.

Reprint requests: Boris Tabakoff, Ph.D., Department of Pharmacology, University of Colorado Health Sciences Center, 4200 East Ninth Avenue, Campus Box C-236, Denver, CO 80262; Fax: 303-315-7097; E-mail: Boris.Tabakoff@UCHSC.edu

Copyright (C) 2000 by the Research Society on Alcoholism. 
developing alcohol dependence have been proposed and investigated, including monoamine oxidase activity (Anthenelli et al., 1995; von Knorring et al., 1991), eventrelated potential P300 amplitude (Keenan et al., 1997), electroencephalographic activity (Bauer and Hesselbrock, 1993), aldehyde dehydrogenase polymorphism (Nakamura et al., 1996), and low level of response to an ethanol challenge (Schuckit et al., 1996). The enzyme adenylyl cyclase (AC) is a biochemical marker that also has been studied for its potential relationship to alcohol dependence. $\mathrm{AC}$ is responsible for the formation of the second messenger adenosine $3^{\prime}: 5^{\prime}$-cyclic monophosphate (cAMP), which in turn acts on a number of target molecules, particularly cAMP-dependent protein kinase, to control such diverse phenomena as metabolism, gene transcription, and memory. AC activity, measured in either platelets (Lex et al., 1993; Saito et al., 1994; Tabakoff et al., 1988) or lymphocytes (Diamond et al., 1987; Nagy et al., 1988; Waltman et al., 1993) of alcohol-dependent subjects, has been shown to be less responsive to agents known to increase enzymatic activity. More recently, low platelet AC activity has been proposed as a trait marker for predisposition to alcohol dependence (Devor et al., 1991; Tabakoff and Hoffman, 1998).

The finding of lower platelet AC activity in alcoholdependent subjects comes with two caveats that need further exploration. First, to demonstrate differences between alcohol-dependent and nondependent subjects, alcoholdependent subjects appear to need a period of abstinence from alcohol. Studies that demonstrate low platelet AC activity in alcohol-dependent subjects all have included subjects who were abstinent for extended periods of time. Tabakoff et al. (1988) assessed alcohol-dependent men who had been abstinent for an average of 23 days and found significantly lower platelet $\mathrm{AC}$ activity when measured in the presence of agents that stimulate AC through the $G_{s}$ protein, that is, cesium fluoride $(\mathrm{CsF})$ and the guanine nucleotide analog 5'-guanylyl-imidodiphosphate, or Gpp(NH)p. Some of the subjects with the lowest CsF-stimulated AC activity in this study were abstinent for 12 to 48 months. Lex et al. (1993) reported significantly lower AC activity when $\mathrm{AC}$ was stimulated by either a guanine nucleotide or $\mathrm{CsF}$ in alcohol-dependent women who had an average of 3.9 years of sobriety. In another study of platelet AC activity in alcohol-dependent subjects, Saito et al. (1994) listed a minimum of at least 1 year of abstinence in their criteria for study entry. In a study that investigated platelet AC activity in subjects who were recovering from heavy drinking, we recently demonstrated that low platelet AC activity (CsF-stimulated) seen in alcohol-dependent subjects was not present immediately after cessation of heavy drinking but became evident after abstinence of 1 to 2 weeks (Menninger et al., 1998).

Second, family history for alcohol dependence appears to be important in determining low platelet AC activity. We reported that low CsF-stimulated platelet $\mathrm{AC}$ activity was significantly associated with a history of alcohol dependence in first-degree relatives among both sober alcoholdependent subjects and control subjects (Menninger et al., 1998). Our finding corroborated the results of others who reported lower AC activity associated with familial alcoholism. Lex et al. (1993) noted significantly lower basal, Gpp(NH)p-stimulated, and CsF-stimulated platelet AC activity among female non-alcohol-dependent controls who were family history positive (FHP) for alcohol dependence, compared with those who were family history negative (FHN). In a separate study of alcohol-dependent men, the FHP alcohol-dependent men had significantly lower $\mathrm{Gpp}(\mathrm{NH})$ p-stimulated platelet AC activity than either the control group or the FHN alcohol-dependent group (Saito et al., 1994). In a recent study of platelet AC in young children of alcoholics, Ratsma et al. (1999) reported reduced platelet AC activity when assayed in the presence of fluoride ion in these children, compared with controls, which further supported AC activity as a trait marker for predisposition to alcoholism. However, in none of the studies to date has platelet AC activity been investigated in a large group of subjects to determine the diagnostic utility of the AC measure for distinguishing alcohol-dependent subjects.

In 1988, the WHO/ISBRA Collaborative Project on State and Trait Markers of Alcoholism was established. Investigators from the International Society for Biomedical Research on Alcoholism (ISBRA) and the National Institute on Alcohol Abuse and Alcoholism (NIAAA) and representatives of the World Health Organization (WHO) collaboratively agreed to pursue a research project focused on (1) the characterization of alcohol dependence in different countries and (2) the substantiation of biological state and trait markers for alcohol dependence. In this paper we present data about platelet AC activity in 210 Australian men that were collected as part of the WHO/ ISBRA Study on State and Trait Markers of Alcoholism. The extensive characterization of this population-based sample of subjects allowed us to examine variables such as level of alcohol consumption, length of abstinence, history of alcohol dependence, other medical and psychiatric conditions, and changes in state markers of alcohol consumption in relation to platelet $\mathrm{AC}$ activity.

\section{METHODS}

\section{Subjects}

Altogether, 285 Australian men were interviewed by research staff who had been trained to use the WHO/ISBRA Interview Schedule. Subjects included 32 men admitted to the Detoxification Unit of Royal Prince Alfred Hospital for alcohol treatment and 253 men who responded to research solicitations. Platelet AC activities were missing in 34 of the subjects, due to either loss of samples from thawing during shipment from Australia or inadequate amount of platelet protein in the sample. They were therefore excluded, together with 41 non-White subjects (because the 32 non-White nondrinkers had significantly different mean platelet AC activities compared with their White counterparts). The studied sample thus comprised 210 White men. 
Subjects were segregated into four categories on the basis of the information elicited in the complete interview: nondrinkers, light/moderate drinkers, heavy drinkers, and patients who were receiving treatment for alcohol dependence. Subjects were considered nondrinkers if they stated that they had never had a 1-year period during which they consumed at least nine drinks. Subjects were classified as light/moderate or heavy drinkers if their reported weekly alcohol consumption during the past 3 months was below or above, respectively, a cutoff of $210 \mathrm{~g}$ of ethanol (i.e., less or greater than 15.4 drinks per week). Alcohol-dependent subjects met DSM-IV criteria for alcohol dependence (American Psychiatric Association, 1994).

Exclusion criteria included major medical and psychiatric disorders, intravenous drug abuse, and recent (past 10 days) treatment with aldehyde dehydrogenase inhibitors (e.g., disulfiram).

\section{Interview}

The WHO/ISBRA Interview Schedule is a structured interview schedule composed of the following major sections: (1) sociodemographic background information; (2) lifetime and past 30 day occurrence of medical conditions; (3) frequency and quantity of beverage-specific alcohol consumption during the past 30 days and during the period when the subject was drinking most heavily; (4) various symptoms experienced with drinking, and information on alcohol-related treatment history; (5) frequency, quantity, and duration of smoking during the past 30 days and the period of heaviest smoking; (6) history of prescription and illicit drug use; (7) history of depression, antisocial behaviors, and treatment for mental or emotional problems; and (8) family history of alcohol and drug problems, major depression, and antisocial behaviors in the biological first- and second-degree relatives. The Interview Schedule was adapted from the Alcohol Use Disorders and Associated Disabilities Interview Schedule developed by the NIAAA (Grant et al., 1995) and was translated into Finnish, Japanese, French, and Portuguese versions for the purpose of this study.

The WHO/ISBRA Interview Schedule enables diagnoses to be extracted according to DSM-IV and International Classification of Diseases (ICD)-10 criteria for the following conditions: alcohol abuse, alcohol dependence, abuse of and dependence on other psychoactive substances (including sedatives and tranquilizers; heroin, methadone, and other opiates; stimulants and cocaine; cannabis; inhalants; hallucinogens; and anabolic steroids), major depression, antisocial personality disorder, and conduct disorder. The test-retest kappa values, the best measure of agreement for categorical data, of the major data elements that appear in the WHO/ISBRA Interview Schedule range from a low of 0.55 for items such as DSM-IV diagnosis of marijuana dependence to values of 1.0 for family history of alcohol dependence in the biological mother. The kappa values for various alcohol dependence criteria in the respondents ranged from 0.70 to 0.90 and 0.60 to 0.80 for DSM-IV and ICD-10 diagnosis of alcohol abuse and dependence (Grant et al., 1995; Tabakoff, 1996).

\section{Blood and Urine Samples}

Blood and urine samples were collected at the time of the interview. Blood was collected via standard venipuncture technique into vacutainers that contained ethylenediaminetetraacetic acid (EDTA) for preparation of plasma and platelets. Within $2 \mathrm{hr}$ of collection, the platelets were prepared by centrifuging the blood samples at $700 \times g$ for $10 \mathrm{~min}$ at room temperature $\left(21 \pm 3^{\circ} \mathrm{C}\right)$. The platelet-rich plasma layer was transferred to a fresh centrifuge tube and again centrifuged for $10 \mathrm{~min}$ at $700 \times g$ at room temperature. The upper platelet-rich layer was then transferred to a fresh centrifuge tube and centrifuged at $2800 \times g$ for $15 \mathrm{~min}$ at room temperature. The platelet pellet was recovered and stored at $-70^{\circ} \mathrm{C}$ until being shipped in dry ice to the Coordinating Center in Helsinki, Finland, and from there to Denver, Colorado, for analysis. The supernatant from the platelet pellets was recovered as the plasma fraction, frozen, and shipped in dry ice to the Helsinki Coordinating Center and assayed for plasma ethanol, $\gamma$-glutamyltransferase (GGT), and aspartate aminotransferase (AST) activities at the laboratories of ALKO and KTL, Helsinki, Finland.
The urine samples were frozen and shipped via the Helsinki Coordinating Center to the Alcohol Diagnostic Laboratory at St. Gorans Hospital, Stockholm, Sweden, for assay of 5-hydroxytryptophol/5-hydroxyindoleacetic acid (5-HTOL/5-HIAA) ratios. A separate vacutainer for preparation of serum was drawn, and the serum was frozen, shipped, and assayed for carbohydrate-deficient transferrin (CDT) levels in the Alcohol Diagnostic Laboratory at St. Gorans Hospital, Stockholm, Sweden.

\section{Preparation of Platelet Membranes}

Before assay of platelet $\mathrm{AC}$ activity, the platelet pellet was thawed and washed at $4^{\circ} \mathrm{C}$. For washing, the platelet pellet was suspended in $1.5 \mathrm{ml}$ of $50 \mathrm{mM}$ Tris- $\mathrm{HCl}(\mathrm{pH} 7.5)$ that contained $20 \mathrm{mM}$ EDTA and then centrifuged at $17,000 \times g$ for $10 \mathrm{~min}$. This procedure was repeated, and the platelet pellet was suspended in $1.5 \mathrm{ml}$ of $5 \mathrm{mM}$ Tris- $\mathrm{HCl}(\mathrm{pH} 7.5)$ that contained $5 \mathrm{mM}$ EDTA and was centrifuged at $17,000 \times g$ for $10 \mathrm{~min}$. The platelet pellet then was suspended in $1.5 \mathrm{ml}$ of $5 \mathrm{mM}$ Tris- $\mathrm{HCl}(\mathrm{pH} 7.5)$ that contained $1 \mathrm{mM}$ EDTA by using a hand-held Teflon homogenizer. The homogenate was diluted as necessary with $5 \mathrm{mM}$ Tris- $\mathrm{HCl}(\mathrm{pH} 7.5)$ that contained $1 \mathrm{mM}$ EDTA to attain a protein concentration of approximately 200 to $1000 \mu \mathrm{g} / \mathrm{ml}$ and was used immediately for the assays of platelet AC activity. Protein determinations were performed by using the Pierce bicinchoninic acid protein microtiter method (Smith et al., 1985).

\section{Adenylyl Cyclase Assay}

Approximately 10 to $50 \mu \mathrm{g}$ of the prepared platelet membrane protein $(50 \mu \mathrm{l})$ was added to $200 \mu \mathrm{l}$ of assay buffer that consisted of $25 \mathrm{mM}$ Tris-maleate $(\mathrm{pH} 7.5), 10 \mathrm{mM}$ theophylline, $5 \mathrm{mM} \mathrm{MgCl}_{2}, 0.25 \mathrm{mM}$ adenosine triphosphate (ATP), and $\left[\alpha^{-32} \mathrm{P}\right] \mathrm{ATP}\left(1.2\right.$ to $2.0 \times 10^{6} \mathrm{cpm} /$ assay). AC activity was measured in duplicate under four separate conditions: basal activity, and with the addition of $10 \mu \mathrm{M} \mathrm{Gpp(NH)p,} 10 \mathrm{mM}$ $\mathrm{CsF}$, or $10 \mu \mathrm{M}$ forskolin. After equilibration of the assay mixture at $30^{\circ} \mathrm{C}$ for $5 \mathrm{~min}$, the reaction was initiated by adding the platelet membranes, and the reaction mixture was incubated at $30^{\circ} \mathrm{C}$ for $10 \mathrm{~min}$. The reaction was terminated by the addition of $750 \mu \mathrm{l}$ of ice-cold solution that contained $4 \mathrm{mM}$ ATP, $1.4 \mathrm{mM}$ cAMP, and 10,000 cpm [ $\left.{ }^{3} \mathrm{H}\right] \mathrm{cAMP}(25-40$ $\mathrm{Ci} / \mathrm{mmol})$ to each assay tube. $\left[{ }^{3} \mathrm{H}\right] \mathrm{cAMP}$, together with $\left[{ }^{32} \mathrm{P}\right]$ cAMP generated by $\mathrm{AC}$, was isolated by sequential chromatography on Dowex and alumina columns as described by Salomon et al. (1974) and quantified by liquid scintillation counting.

All reported values were corrected for recovery of $\left[{ }^{3} \mathrm{H}\right] \mathrm{cAMP}$, and AC activity was expressed as picomoles of cAMP generated per milligram of protein per minute. An aliquot of human erythroleukemia (HEL) cell membranes with known and stable levels of AC activity was assayed with each group of samples. The HEL cell membrane preparation was used as a reference standard to reduce between-assay variability. The value of the AC activity obtained with HEL cell membranes within each day's assay was divided by the HEL cell membrane activity averaged over the entire project period. The resulting factor was applied to each individual's platelet AC activity result obtained on a particular day to standardize all AC activity values obtained throughout the study period. Intraassay coefficients of variation for the AC activity assay performed in our laboratory have been reported to be $14.0 \%$ for basal AC activity, $4.3 \%$ for CsFstimulated AC activity, and $5.0 \%$ for forskolin-stimulated AC activity. Without the use of the HEL cell membrane standardization factor, interassay coefficients of variability for the respective AC activities in our laboratory have been reported at $23.4 \%, 9.2 \%$, and $13.5 \%$ (Menninger and Tabakoff, 1997). With the use of the HEL cell membrane standardization factor, interassay coefficients of variability were found to be $15.4 \%$, $10.8 \%$, and $11.9 \%$ for basal, CsF-stimulated, and forskolin-stimulated AC activity, respectively.

\section{GGT and AST Assays}

Plasma GGT and AST activities were determined by reflectance spectrophotometry by using a Vitros 250 Analyser (Ortho Clinical Diagnos- 
Table 1. Demographic Characteristics Based on Postinterview Classification of Subjects

\begin{tabular}{|c|c|c|c|c|c|}
\hline & Nondrinkers & $\begin{array}{l}\text { Light/moderate } \\
\text { drinkers }\end{array}$ & Heavy drinkers & $\begin{array}{c}\text { Drinkers } \\
\text { without alcohol } \\
\text { dependence }\end{array}$ & $\begin{array}{l}\text { Drinkers with } \\
\text { lifetime alcohol } \\
\text { dependence* }\end{array}$ \\
\hline No. of subjects & 41 & 46 & 123 & 56 & 113 \\
\hline Age (years) & $43.6 \pm 13.4$ & $37.3 \pm 11.5$ & $39.1 \pm 13.7$ & $39.4 \pm 13.0$ & $38.3 \pm 13.2$ \\
\hline \multicolumn{6}{|l|}{ Marital status* } \\
\hline Married & 27 (66\%) & $24(52 \%)$ & $46(37 \%)$ & $31(55 \%)$ & 39 (34\%) \\
\hline Separated & $1(3 \%)$ & $6(13 \%)$ & $31(25 \%)$ & $9(16 \%)$ & $28(25 \%)$ \\
\hline Never married & $13(32 \%)$ & $16(35 \%)$ & $46(37 \%)$ & $16(29 \%)$ & $46(41 \%)$ \\
\hline \multicolumn{6}{|l|}{ Education } \\
\hline High school or less & $14(34 \%)$ & $13(26 \%)$ & $42(34 \%)$ & $16(29 \%)$ & 38 (34\%) \\
\hline Undergraduate & $18(44 \%)$ & $31(67 \%)$ & $71(58 \%)$ & $33(59 \%)$ & $69(61 \%)$ \\
\hline Postgraduate & $9(22 \%)$ & $3(7 \%)$ & $10(8 \%)$ & 7 (13\%) & $6(5 \%)$ \\
\hline \multicolumn{6}{|l|}{ Religion } \\
\hline Protestant & $16(40 \%)$ & $20(44 \%)$ & $55(46 \%)$ & $28(50 \%)$ & $47(42 \%)$ \\
\hline Catholic & $9(22 \%)$ & $16(35 \%)$ & 35 (58\%) & $14(25 \%)$ & 37 (33\%) \\
\hline Jewish & $1(3 \%)$ & $1(2 \%)$ & $2(2 \%)$ & $2(4 \%)$ & $1(1 \%)$ \\
\hline None & $1(3 \%)$ & $6(13 \%)$ & $25(21 \%)$ & $9(16 \%)$ & $22(20 \%)$ \\
\hline Other & $13(32 \%)$ & $3(7 \%)$ & $4(3 \%)$ & $3(5 \%)$ & $4(4 \%)$ \\
\hline \multicolumn{6}{|l|}{ Area where now live } \\
\hline Inner city & $5(12 \%)$ & $8(17 \%)$ & $33(27 \%)$ & $6(11 \%)$ & 35 (31\%) \\
\hline Suburban city & $30(73 \%)$ & $29(63 \%)$ & $80(66 \%)$ & $41(73 \%)$ & $68(61 \%)$ \\
\hline Other & $6(15 \%)$ & $9(20 \%)$ & $9(17 \%)$ & $9(16 \%)$ & $9(8 \%)$ \\
\hline Weight (kg) & $78.3 \pm 14.8$ & $80.6 \pm 10.2$ & $80.4 \pm 14.3$ & $80.1 \pm 11.7$ & $80.6 \pm 14.1$ \\
\hline \multicolumn{6}{|l|}{ Tobacco use } \\
\hline Current smoker & $3(8 \%)$ & $8(17 \%)$ & $65(53 \%)$ & $13(23 \%)$ & $60(53 \%)$ \\
\hline Lifetime smoker & $9(23 \%)$ & $25(54 \%)$ & $93(76 \%)$ & $29(52 \%)$ & 89 (79\%) \\
\hline \multicolumn{6}{|l|}{ Alcohol dependence } \\
\hline Current* & - & $6(13 \%)$ & $81(66 \%)$ & - & 87 (77\%) \\
\hline Lifetime & - & $19(41 \%)$ & $94(76 \%)$ & - & $113(100 \%)$ \\
\hline Never & $41(100 \%)$ & 27 (59\%) & $29(24 \%)$ & $56(100 \%)$ & - \\
\hline
\end{tabular}

* Alcohol dependence refers to DSM-IV alcohol dependence; married includes living with someone as if married and domestic partner relationships; separated includes separated, divorced, and widowed: current refers to in the past year. Values are means \pm SD or frequency and percentage.

tics, Raritan, NJ). Values were considered elevated if $>50$ Units/liter for AST and $>80$ Units/liter for GGT.

\section{CDT Assays}

Serum CDT determinations were carried out in duplicate by using the commercially available CDTect ${ }^{\text {(Ii) }}$ test (Pharmacia Diagnostics, Uppsala, Sweden, and Axis Biochemicals, Oslo, Norway) based on the separation of transferrin isoforms on an anion exchange chromatography microcolumn followed by a double antibody radioimmunoassay. CDT levels $>20$ Units/ liter were considered elevated.

\section{Plasma Ethanol Determinations}

Ethanol determinations in plasma samples were carried out by headspace gas chromatography essentially as described by Roine et al. (1989). Analytical conditions were as follows: column 60/80 Carbopack B/5\% Carbowax $(20 \mathrm{~m}, 6 \mathrm{ft} \times 2 \mathrm{~mm}$ inner diameter; Supelco, Bellefonte, PA); oven temperature $75^{\circ} \mathrm{C}$; detector temperature $140^{\circ} \mathrm{C}$; carrier gas $\left(\mathrm{N}_{2}\right)$ at 40 $\mathrm{ml} / \mathrm{min}$. Ethanol levels $>100 \mu \mathrm{mol} /$ liter were taken as positive evidence for the presence of ethanol in plasma.

\section{Urinary 5-HTOL and 5-HIAA Determination}

The level of the serotonin metabolites 5-HTOL and 5-HIAA were determined by using gas chromatographic-mass spectrometric and highperformance liquid chromatographic methods (Beck et al., 1982; Helander et al., 1991; Voltaire et al., 1992). The reference limit applied for a high urinary 5-HTOL/5-HIAA ratio was $>15 \mathrm{pmol} / \mathrm{nmol}$ (Helander et al., 1994).

\section{Statistical Analysis}

Values are given as mean \pm SD unless noted otherwise. We used Student's $t$ tests and analysis of variance to compare mean AC activities across two or more groups, as defined by type of drinker, lifetime alcohol dependence, recent sobriety, and family history for alcohol dependence. Linear contrasts were used to examine linear trends in AC activities related to duration of sobriety. We conducted post hoc tests for multiple pairwise comparisons by using Tukey's Honestly Significant Difference statistic. The 0.05 level of significance was used for each overall comparison. SPSS for Windows version 8.0 (SPSS Inc., Chicago, IL) was used for data analysis. MedCalc version 4.3 (MedCalc Software, Mariakerke, Belgium) was used for receiver operating characteristic (ROC) curve analysis.

\section{Ethical Considerations and Informed Consent}

The study was approved by the Ethics Review Committee of the Royal Prince Alfred Hospital, Sydney, Australia. Informed consent was obtained in writing from all subjects before participation in the study.

\section{RESULTS}

\section{Demographic Characteristics of Subjects}

Table 1 includes demographic characteristics on the 210 subjects. After analyzing the completed interviews, we categorized subjects into nondrinkers, light/moderate drinkers, and heavy drinkers, whereas drinkers also were grouped according to those who did and did not meet criteria for lifetime alcohol dependence. There were no differences in age or body weight among the groups. The heavy drinkers were more likely to be separated, divorced, or widowed, to be less well educated, to live in an inner city, and to have smoked tobacco (ever or recently). All of the groups consisted primarily of Protestant and Catholic subjects. 
Table 2. Recent and Heaviest Ethanol Consumption Based on Postinterview Classification of Subjects

\begin{tabular}{|c|c|c|c|c|}
\hline & $\begin{array}{c}\text { Light/moderate } \\
\text { drinkers }\end{array}$ & Heavy drinkers & $\begin{array}{c}\text { Drinkers } \\
\text { without alcohol } \\
\text { dependence }\end{array}$ & $\begin{array}{l}\text { Drinkers with } \\
\text { lifetime alcohol } \\
\text { dependence }^{\star}\end{array}$ \\
\hline No. of subjects & 46 & 123 & 56 & 113 \\
\hline Sobriety (days since last drank) & $5.4 \pm 6.0$ & $1.8 \pm 2.6^{a}$ & $3.4 \pm 5.1$ & $2.4 \pm 3.5$ \\
\hline \multicolumn{5}{|l|}{ Recent drinking (last month) } \\
\hline Avg. daily ethanol consumption $(\mathrm{g})^{\star \star}$ & $14.1 \pm 8.3$ & $118 \pm 92^{a}$ & $50 \pm 56$ & $110 \pm 99^{b}$ \\
\hline$\%$ Ethanol as beer & $69 \pm 32$ & $59 \pm 36$ & $59 \pm 34$ & $63 \pm 36$ \\
\hline$\%$ Ethanol as wine & $24 \pm 29$ & $29 \pm 35$ & $32 \pm 33$ & $25 \pm 34$ \\
\hline \% Ethanol as liquor & $7 \pm 17$ & $12 \pm 22$ & $8 \pm 19$ & $12 \pm 22$ \\
\hline \multicolumn{5}{|l|}{ Heaviest drinking period } \\
\hline Age at onset (years) & $17.8 \pm 2.2$ & $17.9 \pm 4.5$ & $17.8 \pm 2.2$ & $17.9 \pm 4.4$ \\
\hline Duration (months) & $54 \pm 56$ & $62 \pm 77$ & $60 \pm 72$ & $59 \pm 71$ \\
\hline Avg. daily ethanol consumption (g) & $60 \pm 61$ & $195 \pm 192^{a}$ & $78 \pm 82$ & $198 \pm 198^{b}$ \\
\hline
\end{tabular}

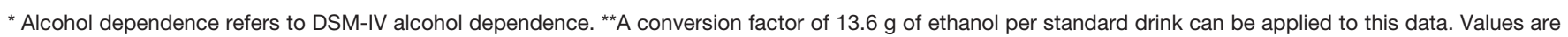

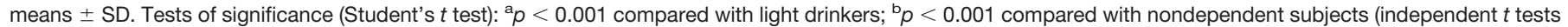
for equality of means assuming unequal variances).

Table 3. Platelet Adenylyl Cyclase Activities

\begin{tabular}{|c|c|c|c|c|}
\hline \multirow[b]{2}{*}{ Subject groups } & \multicolumn{4}{|c|}{ Platelet AC activity $(n)$ (pmol cAMP/mg protein/min) } \\
\hline & Basal & Gpp(NH)p $(10 \mu \mathrm{M})$ & CsF (10 mM) & Forskolin $(10 \mu \mathrm{M})$ \\
\hline Nondrinkers & $15.2 \pm 8.4(40)$ & $73.1 \pm 40.1(41)$ & $127.3 \pm 44.0(39)$ & $367.8 \pm 156.1(39)$ \\
\hline Light/moderate drinkers & $16.4 \pm 5.7(44)$ & $84.7 \pm 20.9(45)$ & $126.4 \pm 23.3(46)$ & $353.5 \pm 84.3(46)$ \\
\hline Heavy drinkers & $17.4 \pm 6.5(123)$ & $82.6 \pm 27.1(121)$ & $129.9 \pm 28.1(123)$ & $387.6 \pm 105.7(122)$ \\
\hline Lifetime alcohol dependence & $17.1 \pm 6.5(113)$ & $80.3 \pm 26.1(111)$ & $128.2 \pm 29.2(113)$ & $375.5 \pm 112.2(112)$ \\
\hline No lifetime alcohol dependence & $16.5 \pm 7.2(94)$ & $82.2 \pm 32.4(96)$ & $129.2 \pm 32.5(95)$ & $377.2 \pm 115.0(95)$ \\
\hline
\end{tabular}

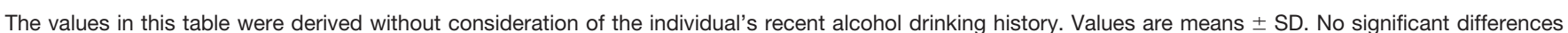
between groups were noted by ANOVA.

\section{Alcohol Dependence and Recent Alcohol Consumption}

After analyzing the complete interviews, we categorized $27 \%$ of the alcohol drinkers as light/moderate drinkers and $73 \%$ as heavy drinkers. Nineteen $(41 \%)$ of the light/moderate drinkers met lifetime criteria for DSM-IV alcohol dependence, compared with 94 (76\%) of the heavy drinkers, for a total of 113 alcohol-dependent subjects.

Recent and heaviest alcohol consumption of the subject groups is listed in Table 2. The light/moderate drinkers had a significantly higher mean duration of recent sobriety than the heavy drinkers. The light/moderate drinkers drank a greater proportion of beer and a smaller proportion of hard liquor in the last month compared with the heavy drinkers, although this difference was not significant. They also drank significantly less ethanol during their heaviest period of drinking than the heavy drinkers. The proportion of alcohol beverage type (beer, wine, or liquor) consumed was similar between drinkers with a lifetime history of alcohol dependence and nondependent drinkers, although the alcohol-dependent group drank more ethanol both in the last month and during their heaviest period of drinking.

\section{Comorbid Drug Dependence}

Few of the alcohol-dependent subjects had additional lifetime dependence on drugs other than alcohol and nicotine. Nine met criteria for cannabis dependence; four for heroin dependence; two each for dependence on sedatives, tranquilizers, and other opiates; and one each for dependence on cocaine, methadone, inhalants, and hallucino- gens. None of the non-alcohol-dependent drinkers or nondrinkers had a history of any abuse of or dependence on these drugs.

\section{Platelet AC Activity}

On initial examination, the platelet AC activities were not statistically different among any of the three drinkerlevel groups (Table 3). There were also no significant differences in any of the platelet AC activities between subjects with a lifetime history of alcohol dependence and those without.

\section{Platelet AC Activity: Effects of Abstinence}

The group of alcohol drinkers was subdivided into current and abstaining drinkers by self-report (by using cutoffs ranging from 2 to 7 days of abstinence, Table 4). Significant differences in basal, CsF-stimulated, and forskolinstimulated platelet AC activities were noted between abstaining and current drinkers. After 4 days of abstinence, both mean CsF- and forskolin-stimulated AC activities remained constant and lower in the abstinent drinkers. For the remainder of this article, the term abstinent will refer to individuals who had not consumed ethanol for at least 4 days.

Alcohol drinkers also were divided into two groups defined by normal and elevated levels of several state biochemical markers for alcohol consumption: plasma ethanol, urinary 5-HTOL/5-HIAA ratio, serum CDT, and plasma GGT and AST (Table 5). Classifying the alcohol- 
Table 4. Platelet Adenylyl Cyclase Activities as a Function of Self-Reported Abstinence in Alcohol Drinkers

\begin{tabular}{|c|c|c|c|c|}
\hline \multirow[b]{2}{*}{ Subject groups } & \multicolumn{4}{|c|}{ Platelet AC activity $(n)$ (pmol cAMP/mg protein/min) } \\
\hline & Basal & Gpp(NH)p (10 $\mu \mathrm{M})$ & $\mathrm{CsF}(10 \mathrm{mM})$ & Forskolin $(10 \mu \mathrm{M})$ \\
\hline Abstinent at least 2 days & $15.6 \pm 6.2(70)^{\mathrm{c}}$ & $81.4 \pm 27.0(68)$ & $124.4 \pm 26.0(71)^{\mathrm{c}}$ & $344.4 \pm 93.2(70)^{d}$ \\
\hline Drank in the last 2 days & $18.6 \pm 6.1(89)$ & $86.6 \pm 24.3(89)$ & $134.6 \pm 26.2(89)$ & $410.6 \pm 97.8(89)$ \\
\hline Abstinent at least 3 days & $14.9 \pm 6.4(44)^{\mathrm{c}}$ & $81.4 \pm 26.3(42)$ & $123.2 \pm 26.0(45)^{a}$ & $336.3 \pm 90.9(44)^{d}$ \\
\hline Drank in the last 3 days & $18.1 \pm 6.1(115)$ & $85.4 \pm 25.3(115)$ & $132.8 \pm 26.3(115)$ & $398.8 \pm 99.7(115)$ \\
\hline Abstinent at least 4 days & $14.3 \pm 5.1(29)^{\mathrm{c}}$ & $79.0 \pm 20.5(28)$ & $116.8 \pm 20.8(30)^{d}$ & $319.2 \pm 80.7(30)^{d}$ \\
\hline Drank in the last 4 days & $17.9 \pm 6.4(130)$ & $85.4 \pm 26.4(129)$ & $133.2 \pm 26.8(130)$ & $396.0 \pm 100.0(129)$ \\
\hline Abstinent at least 5 days & $14.6 \pm 5.0(21)^{\mathrm{a}}$ & $80.6 \pm 18.9(21)$ & $118.1 \pm 18.4(22)^{\mathrm{c}}$ & $323.3 \pm 72.5(22)^{d}$ \\
\hline Drank in the last 5 days & $17.7 \pm 6.4(138)$ & $84.9 \pm 26.5(136)$ & $132.0 \pm 27.1(138)$ & $390.8 \pm 102.0(137)$ \\
\hline Abstinent at least 6 days & $14.6 \pm 4.9(18)^{\mathrm{a}}$ & $79.7 \pm 19.0(18)$ & $118.4 \pm 19.7(19)^{a}$ & $322.2 \pm 76.4(19)^{\mathrm{c}}$ \\
\hline Drank in the last 6 days & $17.6 \pm 6.4(141)$ & $84.9 \pm 26.3(139)$ & $131.7 \pm 26.9(141)$ & $389.5 \pm 101.5(140)$ \\
\hline Abstinent at least 7 days & $14.0 \pm 4.4(17)^{\mathrm{c}}$ & $77.9 \pm 17.9(17)$ & $116.8 \pm 19.0(18)^{\mathrm{b}}$ & $317.2 \pm 75.3(18)^{d}$ \\
\hline Drank in the last 7 days & $17.7 \pm 6.4(142)$ & $85.1 \pm 26.3(140)$ & $131.8 \pm 26.9(142)$ & $389.7 \pm 101.2(141)$ \\
\hline
\end{tabular}

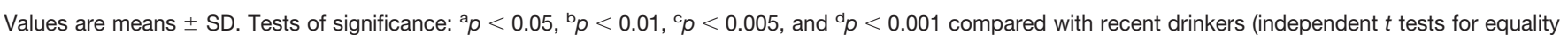
of means assuming unequal variances).

Table 5. Platelet Adenylyl Cyclase Activities in Alcohol Drinkers in Relation to Biochemical Markers of Recent Drinking

\begin{tabular}{|c|c|c|c|c|}
\hline \multirow[b]{2}{*}{ Subject groups } & \multicolumn{4}{|c|}{ Platelet AC activity $(n)$ (pmol cAMP/mg protein/min) } \\
\hline & Basal & Gpp(NH)p (10 $\mu \mathrm{M})$ & CsF (10 mM) & Forskolin $(10 \mu \mathrm{M})$ \\
\hline No detectable ethanol & $17.3 \pm 6.5(146)$ & $83.2 \pm 25.6(146)$ & $128.6 \pm 26.8(148)$ & $377.0 \pm 100.1(148)$ \\
\hline Positive ethanol level & $16.3 \pm 5.3(21)$ & $83.2 \pm 25.8(20)$ & $131.3 \pm 27.7(21)$ & $387.9 \pm 111.9(20)$ \\
\hline Normal 5-HTOL/5-HIAA & $16.8 \pm 6.9(113)$ & $82.9 \pm 27.7(113)$ & $126.5 \pm 27.0(115)$ & $366.2 \pm 102.0(115)^{a}$ \\
\hline Elevated 5-HTOL/5-HIAA & $17.9 \pm 4.8(54)$ & $84.0 \pm 20.3(53)$ & $134.1 \pm 26.1(54)$ & $404.4 \pm 95.4(53)$ \\
\hline Normal CDT level & $16.7 \pm 6.3(112)$ & $82.9 \pm 26.1(112)$ & $125.5 \pm 25.8(114)^{a}$ & $365.8 \pm 100.4(114)^{a}$ \\
\hline Elevated CDT level & $18.2 \pm 6.2(55)$ & $83.8 \pm 24.4(54)$ & $136.2 \pm 27.8(55)$ & $404.6 \pm 98.7(54)$ \\
\hline Normal GGT level & $17.0 \pm 6.4(133)$ & $82.8 \pm 26.4(134)$ & $128.9 \pm 27.6(135)$ & $378.4 \pm 103.8(135)$ \\
\hline Elevated GGT level & $17.7 \pm 5.8(34)$ & $84.9 \pm 21.8(32)$ & $129.1 \pm 24.1(34)$ & $377.8 \pm 91.6(33)$ \\
\hline Normal AST level & $17.2 \pm 6.3(137)$ & $82.9 \pm 25.7(138)$ & $128.8 \pm 26.3(139)$ & $379.0 \pm 101.0(139)$ \\
\hline Elevated AST level & $17.7 \pm 5.7(29)$ & $86.7 \pm 23.6(27)$ & $132.2 \pm 27.4(29)$ & $382.4 \pm 96.8(28)$ \\
\hline
\end{tabular}

Elevated marker levels are defined as follows: 5-HTOL/5-HIAA > 15 pmol/nmol; CDT > 20 Units/liter; GGT > 80 Units/liter; and AST > 50 Units/liter. Values are

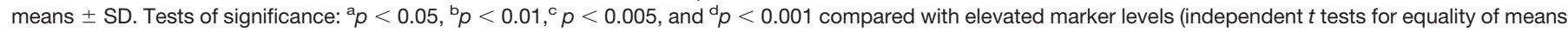
assuming unequal variances).

Table 6. Platelet Adenylyl Cyclase Activities in Self-Reported Abstinent* Drinkers: Relation to Lifetime and Current Alcohol Dependence

\begin{tabular}{|c|c|c|c|c|}
\hline \multirow[b]{2}{*}{ Subject groups } & \multicolumn{4}{|c|}{ Platelet AC Activity (n) (pmol cAMP/mg protein/min) } \\
\hline & Basal & Gpp(NH)p (10 $\mu \mathrm{M})$ & CsF (10 mM) & Forskolin $(10 \mu \mathrm{M})$ \\
\hline Lifetime alcohol dependence & $13.6 \pm 5.6(16)$ & $72.5 \pm 21.6(15)$ & $106.8 \pm 18.8(16)^{b}$ & $286.8 \pm 75.6(16)^{a}$ \\
\hline No lifetime alcohol dependence & $15.1 \pm 4.5(13)$ & $86.6 \pm 16.9(13)$ & $128.2 \pm 17.1(14)$ & $356.3 \pm 71.8(14)$ \\
\hline Current alcohol dependence & $12.2 \pm 4.5(12)$ & $68.5 \pm 21.8(11)$ & $103.6 \pm 18.0(12)^{b}$ & $279.5 \pm 77.0(12)^{\mathrm{a}}$ \\
\hline No current alcohol dependence & $15.8 \pm 5.1(17)$ & $85.8 \pm 17.0(17)$ & $125.6 \pm 18.0(18)$ & $345.7 \pm 73.7(18)$ \\
\hline
\end{tabular}

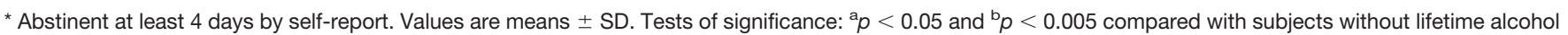
dependence (independent $t$ tests for equality of means assuming unequal variances).

consuming subjects on the basis of a positive plasma ethanol level, or elevation of either of the hepatic enzymes, GGT or AST, yielded no significant differences in mean platelet AC activity. On the other hand, in the alcoholconsuming subjects, normal 5-HTOL/5-HIAA ratios were associated with significantly lower mean forskolinstimulated platelet AC activity, and normal CDT levels were associated with significantly lower mean CsF- and forskolin-stimulated platelet AC activities.

\section{Platelet AC Activity: Effects of Alcohol Dependence}

Among subjects who were currently abstinent $(>4$ days without alcohol), those with a history of alcohol dependence had significantly lower mean CsF- and forskolin-stimulated platelet AC activities $(p<0.005$ and $<0.05$, respectively). Similar significant findings were noted for those subjects with current (i.e., past year) alcohol dependence (Table 6). Such differences were not seen among those subjects who had been drinking within 4 days of the assessment, whether the comparison was for lifetime or current alcohol dependence. Figure 1 further illustrates the relationship between current drinking, lifetime history of alcohol dependence, and platelet AC activity. Irrespective of whether basal, CsF-stimulated, or forskolin-stimulated AC activity was being measured, the lowest values were noted in the group of subjects who had been abstinent for at least 4 days and who had a lifetime history of alcohol dependence. When $\operatorname{Gpp}(\mathrm{NH}) \mathrm{p}$ was used as a means of stimulating platelet $\mathrm{AC}$ activity, the results were not definitive because nondrinkers also displayed low enzymatic activity under these assay conditions. 

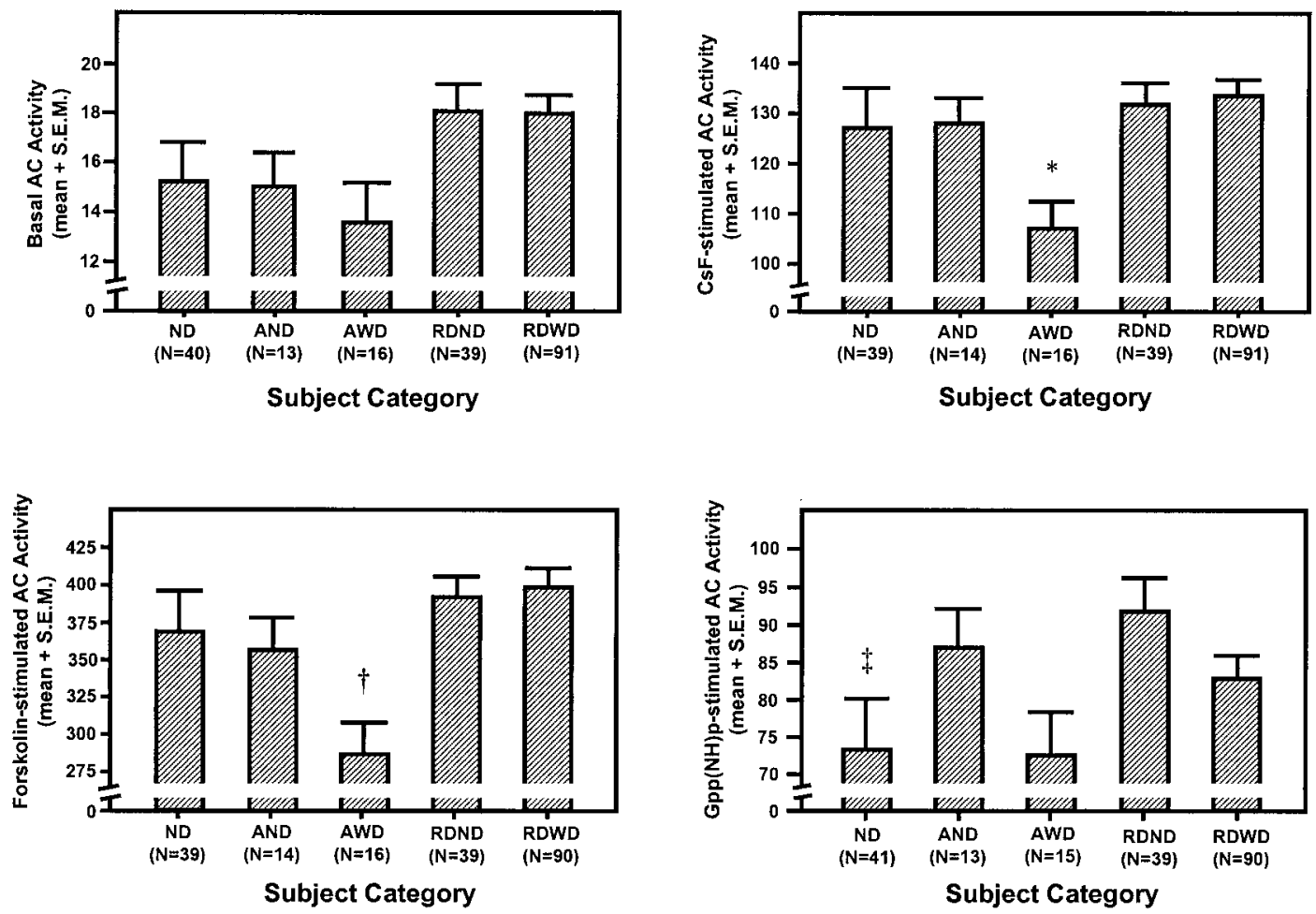

Fig. 1. Effect of abstinence and lifetime DSM-IV alcohol dependence on platelet adenylyl cyclase activity. One-way ANOVA of platelet AC activity and subject category was performed (ND, nondrinker; AND, abstinent drinker with no alcohol dependence; AWD, abstinent drinker with alcohol dependence; RDND, recent drinker with no alcohol dependence; RDWD, recent drinker with alcohol dependence). Values are presented as mean \pm SEM. Platelet AC activity is expressed in picomoles of cAMP per milligram of protein per minute. Post hoc tests of significance: ${ }^{*} C s F-$ stimulated AC activity: AWD vs. RDND, $p<0.05$, and AWD vs. RDWD, $p<0.01$. ${ }^{\dagger}$ Forskolin-stimulated AC activity: AWD vs. RDND, $p<0.05$, and AWD vs. RDWD, $p<0.005$. ${ }^{\ddagger}$ Gpp(NH)p-stimulated AC activity: ND vs. RDND, $p<0.05$.

Because prior studies did not attempt to examine the diagnostic utility of platelet AC activity, we determined the sensitivity and specificity of CsF-stimulated AC activity for discriminating lifetime alcohol dependence versus no history of alcohol dependence in abstinent drinkers. An ROC analysis showed an area under the curve (AUC) of 0.79 with a $95 \%$ confidence interval (CI) of 0.61 to 0.92 . The optimal cutoff level for CsF-stimulated AC activity was 109 $\mathrm{pmol} \mathrm{cAMP} / \mathrm{mg}$ protein/min, which yielded a sensitivity of $75 \%$ and a specificity of $79 \%$ (Fig. 2). We found similar results for CsF-stimulated AC activity in distinguishing abstinent subjects with current alcohol dependence from those without alcohol dependence $(\mathrm{AUC}=0.81 ; 95 \% \mathrm{CI}=$ $0.62,0.93$; sensitivity $67 \%$ and specificity $83 \%$ at a cutoff of $105 \mathrm{pmol} \mathrm{cAMP} / \mathrm{mg}$ protein/min).

\section{Platelet AC Activity: Effects of Quantity of Alcohol} Consumed, Tobacco Smoking, Age, Body Weight, and Alcohol-Related Behaviors

We also considered a number of other factors that may distinguish alcohol drinkers who had or had not consumed ethanol over the past 4 days (Table 7). The abstinent alcohol drinkers had consumed significantly less ethanol in the past month and during their heaviest drinking period compared with the recent drinkers. However, ethanol quantity, consumed either in the past month or during the heaviest drinking period, did not significantly correlate with

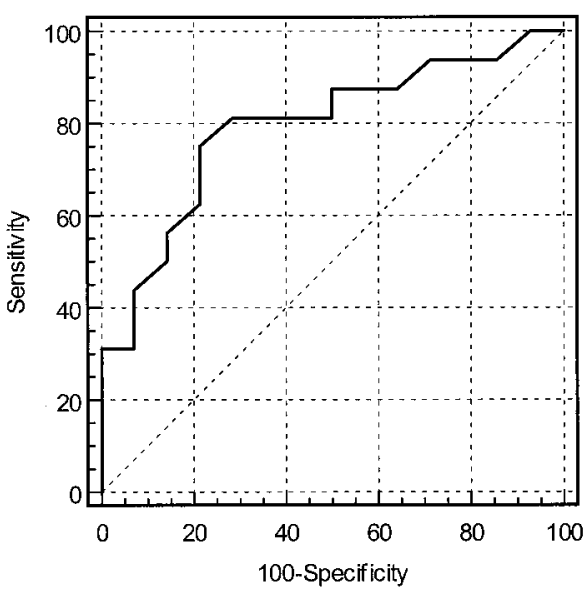

Fig. 2. ROC curve analysis of CSF-stimulated platelet $A C$ activity for determining lifetime alcohol dependence in alcohol drinkers abstinent at least 4 days; 12 subjects with lifetime DSM-IV alcohol dependence and 14 subjects with no history of DSM-IV alcohol dependence.

any of the platelet AC activities (data not shown). As expected, after we adjusted for quantity of ethanol consumed in the past month, the previously noted differences in basal, CsF-stimulated, and forskolin-stimulated AC activity between abstinent and recent drinkers remained statistically significant (data not shown).

There was no difference in almost any of the platelet AC activity measures between current smokers and nonsmokers. Only basal platelet AC activity was significantly differ- 
Table 7. Recent and Heaviest Ethanol Consumption and Tobacco Use of Abstinent* and Recent Male Drinkers

\begin{tabular}{lcc}
\hline & $\begin{array}{c}\text { Abstinent drinkers } \\
(n=30)\end{array}$ & $\begin{array}{c}\text { Recent drinkers } \\
(N=130)\end{array}$ \\
\hline Recent drinking & & \\
$\quad$ Sobriety (days since last drank) & $9.1 \pm 6.0$ & $1.2 \pm 0.9$ \\
$\quad \begin{array}{l}\text { Average daily ethanol consumption last } \\
\quad \text { month (g) }\end{array}$ & $57.4 \pm 91.7^{\mathrm{a}}$ & $100.0 \pm 88.9$ \\
$\quad$ \% Ethanol last month as beer & $63 \pm 38$ & $61 \pm 35$ \\
$\quad \%$ Ethanol last month as wine & $27 \pm 33$ & $27 \pm 33$ \\
$\quad \%$ Ethanol last month as liquor & $11 \pm 20$ & $11 \pm 22$ \\
Heaviest drinking period & & \\
$\quad$ Age at onset (years) & $19.7 \pm 7.2$ & $17.4 \pm 2.4$ \\
$\quad$ Duration (months) & $44.4 \pm 40.4$ & $64.2 \pm 77.3$ \\
$\quad$ Average daily ethanol consumption (g) & $90.1 \pm 110.4^{\mathrm{b}}$ & $179.1 \pm 189.0$ \\
Tobacco use & & \\
$\quad$ Lifetime smokers & $17(57 \%)$ & $97(75 \%)$ \\
$\quad$ Current smokers & $7(23 \%)$ & $63(48 \%)$ \\
$\quad$ Total packs of cigarettes ever smoked & $4500 \pm 5353$ & $6760 \pm 7576$ \\
\hline
\end{tabular}

${ }^{*}$ Abstinent at least 4 days by self-report. Values are reported as means $\pm S D$ or as frequency and percentage. Tests of significance: ${ }^{a} p<0.05$ and ${ }^{b} p<0.005$ compared with recent drinkers (independent $t$ tests for equality of means assuming unequal variances).

ent between abstinent subjects who ever smoked and nonsmokers $(p<0.05$, data not shown), and this difference remained significant even after adjustment for lifetime alcohol dependence.

Forskolin-stimulated AC activity weakly correlated with age in the group of abstinent subjects $(r=0.39, p<0.05$, data not shown), although this correlation disappeared in the overall group of subjects. Forskolin- and CsFstimulated AC activity remained significantly different between recent and abstinent drinkers even after we adjusted for age and body weight. No significant association was seen between any measure of AC activity and alcoholrelated behaviors such as violent behavior during or after drinking (Ikeda et al., 1998).

\section{Platelet AC Activity: Effects of Family History for Alcohol Dependence}

Abstinent alcohol drinkers who were FHP, defined separately as (1) subjects with one or more first- or seconddegree alcohol-dependent relatives and, more strictly, as (2) subjects with both a first- and a second-degree alcoholdependent relative, showed a decline in CsF-and forskolinstimulated platelet AC activity with increasing family loading for alcohol dependence, but the observed differences did not reach significance (Table 8 ).

\section{Platelet AC Activity: Effects of Antisocial Personality Disorder}

Neither antisocial personality disorder nor prior conduct disorder, as defined by DSM-IV, were associated with significant differences in any mean platelet $\mathrm{AC}$ activity, whether the comparisons were among all subjects, all drinkers, or only abstinent drinkers.

\section{Platelet AC Activity: Effects of Major Depression}

A history of major depression, as defined by DSM-IV, was associated with significantly lower levels of forskolin-stimulated platelet $\mathrm{AC}$ activity in the group that consisted of nondrinkers and abstinent drinkers, compared with individuals without any history of depression $(256.2 \pm 76.0$ vs. $382.2 \pm 134.2, p<0.01)$. A ROC analysis of low forskolin-stimulated AC activity for discriminating major depression showed an AUC of 0.79 with a $95 \%$ CI of 0.70 to 0.86 . The optimal cutoff level of $286 \mathrm{pmol} \mathrm{cAMP} / \mathrm{mg}$ protein/min yielded a sensitivity of $83 \%$ and a specificity of $76 \%$. The basal, Gpp(NH)pstimulated, and CsF-stimulated AC activities were not different in subjects with major depression compared with those who had no history of major depression. The results obtained with depressed subjects should be viewed with caution because the number of depressed subjects in this study was small $(n=6)$.

\section{Platelet AC Activity: Effects of Medications and Medical Conditions}

Examination of the effect of various self-reported medical conditions, both in the past 30 days and ever, on mean platelet AC activity in abstinent drinkers and nondrinkers revealed significant effects of hepatomegaly and hyperlipidemia on AC activity. Basal, CsF-stimulated, and forskolin-stimulated $\mathrm{AC}$ activities were significantly lower in the six subjects with a history of liver enlargement compared with 63 subjects without any history of hepatomegaly (data not shown). However, when we accounted for lifetime history of alcohol dependence, no independent effects of hepatomegaly were seen on AC activity. Within the group of abstinent drinkers and nondrinkers, 13 subjects with hyperlipidemia had significantly lower mean platelet Gpp(NH)p- and CsF-stimulated AC activity compared with the 56 subjects without elevated lipids $(60.7 \pm 21.8$ vs. $79.0 \pm 35.0, p<0.05$, and $103.2 \pm 22.7$ vs. $127.6 \pm 37.3, p=$ 0.005 , respectively), although no significant difference in forskolin-stimulated activity was found. Even after we accounted for lifetime history of alcohol dependence, there still remained a significant effect of hyperlipidemia on CsFand $\mathrm{Gpp}(\mathrm{NH}) \mathrm{p}$-stimulated $\mathrm{AC}$ activity. There were no significant differences in mean platelet $\mathrm{AC}$ activity for subjects with hypertension $(n=11)$, hepatitis $(n=3)$, or gastritis $(n=3)$, and no subjects reported a history of cirrhosis or diabetes. The recent use of various medication types, over both the past week and the past month, revealed no significant effects on mean platelet AC activity (data not shown), nor did the reported recent use of various illicit drugs.

\section{CONCLUSIONS}

In this study we report findings on platelet AC activity in a recruited population of alcohol drinkers and nondrinkers. 
Table 8.Platelet Adenylyl Cyclase Activities in Abstinent Drinkers*: Relation to Family History for Alcohol Dependence

\begin{tabular}{|c|c|c|c|c|}
\hline \multirow[b]{2}{*}{ Subject groups } & \multicolumn{4}{|c|}{ Platelet AC Activity $(n)$ (pmol cAMP/mg protein/min) } \\
\hline & Basal & Gpp(NH)p (10 $\mu \mathrm{M})$ & CsF (10 mM) & Forskolin $(10 \mu \mathrm{M})$ \\
\hline $\mathrm{FHN}^{\dagger}$ & $14.0 \pm 5.1(17)$ & $78.1 \pm 21.9(17)$ & $119.6 \pm 21.5(18)$ & $331.9 \pm 88.3(18)$ \\
\hline $\mathrm{FHP}^{\dagger+}$ in a 1 st or 2 nd degree relative & $14.2 \pm 5.4(9)$ & $82.3 \pm 16.6(8)$ & $115.1 \pm 20.4(9)$ & $305.6 \pm 71.0(9)$ \\
\hline $\mathrm{FHP}^{+\dagger}$ in both a 1 st and 2 nd degree relative & $12.0 \pm 5.4(4)$ & $76.3 \pm 9.0(3)$ & $108.2 \pm 22.5(4)$ & $258.0 \pm 68.2(4)$ \\
\hline
\end{tabular}

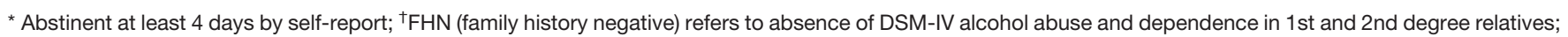

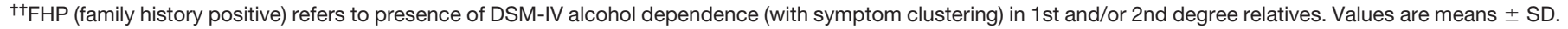
No significant differences between groups were noted by ANOVA.

Because the assessed population consisted of White Australian men, the generalization of our results to women or to other racial/ethnic groups should be undertaken with significant caution. In the abstinent drinkers, CsF- and forskolin-stimulated platelet $\mathrm{AC}$ activities were significantly lower in individuals diagnosed with either current or lifetime alcohol dependence compared with those who had no history of alcohol dependence. The results obtained with CsF mirror the results of prior studies that examined AC activity in abstinent alcohol-dependent subjects, using both platelets (Lex et al., 1993; Parsian et al., 1996; Tabakoff et al., 1988) and lymphocytes (Waltman et al., 1993). Our results obtained with forskolin add yet another dimension to results that demonstrate lower platelet AC activity in alcohol-dependent individuals. Forskolin is a diterpene alkaloid, which binds directly to AC protein and activates the enzyme (Seamon and Daly, 1981). The results of assays with forskolin indicate that the AC enzyme protein may be the determinant of the lower platelet AC activity.

Two other studies of subjects with a lifetime history of alcohol dependence (Saito et al., 1994; Tabakoff et al., 1988) showed that individuals with a history of alcohol dependence, but who had been abstinent for 1 to 4 years, displayed lower CsF-stimulated platelet AC activity compared with individuals who had never been alcohol dependent. Prior work also has focused attention on the fact that individuals with a family history of alcohol dependence display lower platelet AC activity than FHN subjects (Lex et al., 1993; Saito et al., 1994). In the current study, a trend was again evident for lower CsF- and forskolin-stimulated $\mathrm{AC}$ activity in our subjects as the loading for alcohol dependence in their families increased. Additionally, because CsF-stimulated platelet AC activity has been demonstrated to be a heritable trait (Devor et al., 1991), one can consider that low platelet $\mathrm{AC}$ activity may represent a biological "trait" marker for alcohol dependence.

However, recent consumption of alcohol influences the observed levels of platelet AC activity. The effect of recent alcohol consumption on platelet AC activity is evident through comparisons of basal-, CsF-, and forskolinstimulated $\mathrm{AC}$ activity in individuals currently drinking and those reporting abstinence for 2 or more days. The highest levels of AC activity are evident in the self-reported current drinkers, whereas significantly lower levels are evident in the abstaining subjects. The mean values for basal-, CsFstimulated, and forskolin-stimulated activity stabilized at their lowest levels in individuals who reported 4 or more days of abstinence. Similarly, a recent study that serially monitored platelet $\mathrm{AC}$ activity in individuals who recently had ended heavy alcohol consumption (measurements made at 1-3 days, 7 days, and 14 days of monitored abstinence) found that CsF- and forskolin-stimulated platelet $\mathrm{AC}$ activity diminished significantly within 1 week of abstinence, and the levels of AC activity remained constant at 7-day and 14-day assessments (Menninger et al., 1998).

In the current study, a number of biological markers of recent alcohol use were also available to assess abstinence and relate to platelet AC activity. Plasma 5-HTOL/5-HIAA ratios have been reported to remain elevated for 5 to $20 \mathrm{hr}$ after clearance of ethanol from an alcohol-consuming individual (Sillanaukee, 1996). Individuals with elevated 5-HTOL/5-HIAA ratios in the current study had significantly higher forskolin-stimulated platelet AC activity than individuals with normal 5-HTOL/5-HIAA ratios. Serum CDT levels are also a measure of recent alcohol consumption with sensitivity and specificity values equal to or better than those for the conventional laboratory markers (Anton and Moak, 1994; Stibler, 1991). CDT levels have been reported elevated in most individuals who consume ethanol at levels at or exceeding 60 to $80 \mathrm{~g}$ per day for extended periods (Stibler et al., 1986). With abstinence, serum CDT levels normalize with a half-life of about 15 days (Stibler et al., 1991). Individuals with elevated CDT levels in our study also displayed higher levels of CsF- and forskolinstimulated platelet AC activity compared with individuals who had normal CDT levels.

Ethanol metabolism and elimination have been reported to range from 58 to $148 \mathrm{mg} / \mathrm{kg} / \mathrm{hr}$ (Kopun and Propping, 1977), or 4 to $11 \mathrm{~g} / \mathrm{hr}$ in a $70 \mathrm{~kg}$ man, with more rapid metabolism and elimination of ethanol noted in heavy drinkers (Jones, 1993) and chronic alcoholics (Nuutinen et al., 1985). Thus, the quantity of alcohol present in three standard drinks (one standard drink is considered equivalent to $13.6 \mathrm{~g}$ absolute ethanol; Sobell and Sobel, 1992) can be metabolized in 4 to $6 \mathrm{hr}$ in an average male drinker. The presence of plasma ethanol in certain individuals in our study did not differentiate these individuals with regard to their platelet AC activity. If one assumes that regular ethanol consumption elevates certain components of platelet AC activity, then one can hypothesize that normalization of the platelet $\mathrm{AC}$ activity follows a time course that is significantly slower than the time course of ethanol elimination in human males.

Elevated plasma GGT and AST levels also did not dif- 
ferentiate platelet AC activity. The elevated GGT and AST levels in alcohol-consuming individuals in many cases reflect liver damage (Sillanaukee, 1996) rather than alcohol consumption per se. Thus, one can assume that elevated platelet AC activity values may not be a consequence of changes in liver function, which would be reflected by the elevations in plasma GGT and AST.

Overall, by using either self-report of recent alcohol intake or the results of the biological markers (5-HTOL/5HIAA ratios or CDT levels) for measuring recent alcohol intake, the results indicate that recent (within 2-4 days) alcohol intake elevates platelet AC activity when the enzyme is activated by CsF or forskolin. Given that platelet half-life in humans is approximately 4 to 5 days (Gewirtz and Poncz, 1991), one may conjecture that the lowering (normalization) of platelet AC activity after the individual stops drinking alcohol may be related to generation of new platelets during the abstinence period. Interestingly, platelet $\mathrm{AC}$ activity measured in the presence of $\mathrm{Gpp}(\mathrm{NH}) \mathrm{p}$ was not statistically higher in currently alcohol-consuming subjects compared with abstinent subjects. This observation may reflect a lower sensitivity of this assay condition to measure ethanol-induced differences in platelet AC activity, or it may reflect a mechanism of ethanol's actions that leaves unperturbed the path by which $\mathrm{Gpp}(\mathrm{NH}) \mathrm{p}$ activates AC. Although both $\mathrm{CsF}$ and $\mathrm{Gpp}(\mathrm{NH}) \mathrm{p}$ act through $\mathrm{G}$ proteins to modulate $\mathrm{AC}$ activity, their actions are different. $\mathrm{Gpp}(\mathrm{NH}) \mathrm{p}$ is a nonhydrolyzable analog of GTP that displaces GDP and binds to the GTP binding site of G proteins and activates these proteins. On the other hand, the fluoride ion interacts with $\mathrm{G}$ proteins (e.g., $\mathrm{G}_{\mathrm{S}} \alpha$ ) that have GDP bound at the guanine nucleotide binding site and activates this complex by stabilizing the $\mathrm{G}_{\mathrm{S}} \alpha$ transition state responsible for the activation of AC (Skiba and Hamm, 1998).

A final important observation about the effect of recent alcohol consumption on platelet AC activity was that the $\mathrm{AC}$ activity did not correlate with self-report on the quantity of alcohol consumed in the last 30 days. This observation may reflect the difficulty in obtaining accurate information on prior alcohol consumption without using various memory aids (Babor and Del Boca, 1992), or it may reflect the fact that platelet $\mathrm{AC}$ activity is a better reflector of more recent drinking (the preceding 2 to 4 day period) than of drinking that occurred within the past 30 days. However, our interview instrument was not designed to accurately quantify the most recent daily alcohol consumption, and future studies would benefit from using memory-enhancing methods such as the timeline follow-back technique (Sobell and Sobel, 1992) to assess quantitative relations between recent ethanol intake and platelet $\mathrm{AC}$ activity.

Because our subject sample was recruited primarily on the basis of their alcohol consumption habits rather than on the a priori determination of a diagnosis of alcohol dependence, we further assessed the utility of platelet AC activity as a biological marker for distinguishing alcohol-dependent subjects in the abstaining (4 or more days) subject population. A ROC analysis provided a cutoff value for CsFstimulated platelet AC activity that allowed for a sensitivity and specificity of approximately $75 \%$. Although a marker with this level of sensitivity and specificity can be considered of moderate utility in identifying alcohol-dependent subjects in a general population, the current analysis represents one of the first attempts to ascertain the sensitivity and specificity of this putative biological "trait" marker for alcohol dependence.

Other enzymological differences between alcoholdependent and nondependent subjects have been proposed to represent "trait" markers for alcohol dependence, but evidence for their heritability, sensitivity, and specificity is lacking ( $\mathrm{Li}, 1995)$. For example, a link between esterase D polymorphism and alcohol dependence (Tanna et al., 1988) has not been replicated in subsequent studies (Neiswanger et al., 1995; Wesner et al., 1991). More recently, however, genetic analyses have produced a report about a link between an alcoholism-related severity phenotype and microsatellite markers (e.g., D16S675) on chromosome 16 (Foroud et al., 1998). Interestingly, two AC genes are known to be located on chromosome 16: The AC type VII gene is located between 16q12 and 16q13 (Hellevuo et al., 1995), and the AC type IX gene is located at 16p13.3 (Hacker et al., 1998). The gene for AC type IX is located in the same region of chromosome 16 as the D16S675 marker identified by Foroud et al. (1998) (i.e., 16p13.3). It would be of interest to further examine the gene for AC IX and to identify the possible structural or regulatory differences that may contribute to a predisposition for low platelet AC activity.

We again found a relationship between low forskolinstimulated platelet AC activity and a diagnosis of depression in our subjects. Prior work in nondependent individuals demonstrated significantly lower forskolin-stimulated AC activity in subjects with unipolar depression (Menninger and Tabakoff, 1997). Although the current study contained only a limited number of subjects who could be assigned a diagnosis of major depression, the mean value for forskolin-stimulated platelet AC activity in these subjects was significantly lower than in subjects with no history of major depression. The distinguishing feature of the platelet AC activity between the subjects with a history of major depression versus the alcohol-dependent subjects was that the alcohol-dependent subjects were low in both $\mathrm{CsF}$ and the forskolin-stimulated platelet AC activity, whereas the depressed subjects displayed lower forskolinstimulated AC activity in conjunction with normal CsFstimulated activity. Further work in this area may allow for development of a diagnostic tool for distinguishing alcoholdependent subjects with and without comorbid unipolar depression.

The current study also allowed us to examine effects of a number of medical conditions and licit and illicit drug use on platelet AC activity in our subjects. In general, most 
such variables had little or no effect on platelet AC activity. The current study did reveal an altered AC activity in subjects with hepatomegaly, though this effect appeared to be explained by alcohol dependence. Hyperlipidemia, however, appears as an independent factor that results in lower CsF-stimulated AC activity (in abstinent and nondrinker subjects). This observation appears consistent with prior reports of reduced AC activity associated with hypercholesterolemia. Schmidt et al. (1993) and Gerasimova (1977) noted reduced AC activity in smooth muscle and liver tissue, as well as in thrombocytes of hypercholesterolemic rabbits. The effect of hyperlipidemia on platelet AC activity is, however, distinguishable from the effect of alcohol dependence: alcoholism was associated with both low CsFstimulated and low forskolin-stimulated AC values, whereas hyperlipidemia was associated with lower CsFstimulated but not forskolin-stimulated AC activity. Prior studies have reported little association between smoking and platelet AC activity (Menninger et al., 1998; Tabakoff et al., 1988). Similarly, in the current study, although smoking increased basal $\mathrm{AC}$ activity in abstinent drinkers, there was no significant difference in stimulated AC activity levels between smokers and nonsmokers.

In summary, CsF-stimulated platelet AC activity may act as a marker for lifetime incidence of alcohol dependence, as long as the subject is abstinent for 4 days or more before testing. Additional factors that may contribute to low platelet AC activity are depression, hyperlipidemia, and family history of alcohol dependence. Measurements of both forskolin- and CsF-stimulated platelet AC activity may allow researchers to distinguish individuals with a lifetime history of alcohol dependence from those individuals with affective illness and/or hyperlipidemia.

\section{ACKNOWLEDGMENT}

The CDTect kits were kindly supplied by Pharmacia Diagnostics, Uppsala, Sweden, and by Axis Biochemicals, Oslo, Norway. The Australian data collection was carried out by a team of interviewers led by Ms. Nina Savolainen. Ms. Josephine Tsao performed the assays of adenylyl cyclase activity.

\section{REFERENCES}

American Psychiatric Association (1994) Diagnostic and Statistical Manual of Mental Disorders. 4th ed. American Psychiatric Association, Washington, DC.

Anthenelli RM, Smith TL, Craig CE, Tabakoff B, Schuckit MA (1995) Platelet monoamine oxidase activity levels in subgroups of alcoholics: Diagnostic, temporal, and clinical correlates. Biol Psychiatry 38:361368.

Anton RF, Moak DH (1994) Carbohydrate-deficient transferrin and gamma-glutamyltransferase as markers of heavy alcohol consumption: Gender differences. Alcohol Clin Exp Res 18:747-754.

Babor TF, Del Boca FK (1992) Just the facts: Enhancing measurement of alcohol consumption using self-report methods, in Measuring Alcohol Consumption: Psychosocial and Biochemical Methods (Litten RZ, Allen JP eds), pp 3-19. Humana Press, Totowa, NJ.

Bauer LO, Hesselbrock VM (1993) EEG, autonomic and subjective correlates of the risk for alcoholism. J Stud Alcohol 54:577-589.
Beck O, Borg S, Eriksson L, Lundman A (1982) 5-hydroxytryptophol in the cerebrospinal fluid and urine of alcoholics and healthy subjects. Naunyn Schmiedebergs Arch Pharmacol 321:293-297.

Devor EJ, Cloninger CR, Hoffman PL, Tabakoff B (1991) A genetic study of platelet adenylate cyclase activity: Evidence for a single major locus effect in fluoride-stimulated activity. Am J Hum Genet 49:372-377.

Diamond I, Wrubel B, Estrin W, Gordon A (1987) Basal and adenosine receptor-stimulated levels of cAMP are reduced in lymphocytes from alcoholic parents. Proc Natl Acad Sci USA 84:1413-1416.

Foroud T, Bucholz KK, Edenberg HF, Goate A, Neuman RJ, Porjesz B, Koller DL, Rice J, Reich T, Bierut LJ, Cloninger CR, Nurnberger JI Jr, Li T-K, Conneally PM, Tischfield JA, Crowe R, Hesselbrock V, Schuckit M, Begleiter H (1998) Linkage of an alcoholism-related severity phenotype to chromosome 16. Alcohol Clin Exp Res 22:2035-2042.

Gerasimova EN (1977) [Cyclic adenosine monophosphate and atherogenic factors]. Vopr Med Khim 6:789-796.

Gewirtz AM, Poncz M (1991) Megakaryocytopoiesis and platelet production, in Hematology: Basic Principles and Practice (Hoffman R, Benz EJ Jr, Shattil SJ, Furie B, Cohen H. eds), pp 1148-1157. Churchill Livingstone, New York.

Grant BF, Hartford TC, Dawson DA, Chou PS, Pickering RP (1995) The Alcohol Use Disorder and Associated Disabilities Interview Schedule (AUDADIS): Reliability of alcohol and drug modules in a general population sample. Drug Alcohol Depend 39:37-44.

Hacker BM, Tomlinson JE, Wayman GA, Sultana R, Chan G, Villacres E, Disteche C, Storm DR (1998) Cloning, chromosomal mapping, and regulatory properties of the human type 9 adenylyl cyclase (ADCY9). Genomics 50:97-104.

Helander A, Beck O, Borg S (1994) The use of 5-hydroxytryptophol as an alcohol intake marker. Alcohol Alcohol Suppl 2:497-502.

Helander A, Beck O, Wennberg M, Wikstkrom T, Jackobsson G (1991) Determination of urinary 5-hydroxyindole 3-acetic acid by highperformance liquid chromatography with electrochemical detection and direct sample injection. Anal Biochem 196:170-173.

Hellevuo K, Berry R, Sikela JM, Tabakoff B (1995) Localization of the gene for a novel human adenylyl cyclase (ADCY7) to chromosome 16. Hum Genet 95:197-200.

Ikeda H, Menninger JA, Tabakoff B (1998) An initial study of the relationship between platelet adenylyl cyclase activity and alcohol use disorder criteria. Alcohol Clin Exp Res 22:1057-1064.

Jones AW (1993) Disappearance rate of ethanol from the blood of human subjects: Implications in forensic toxicology. J Forensic Sci 38:104-118. [Published erratum appears in J Forensic Sci (1994) 39:591.]

Keenan JP, Freeman PR, Harrell R (1997) The effects of family history, sobriety length, and drinking history in younger alcoholics on P300 auditory-evoked potentials. Alcohol Alcohol 32:233-239.

Kopun M, Propping P (1977) The kinetics of ethanol absorption and elimination in twins and supplementary repetitive experiments in singleton subjects. Eur J Clin Pharmacol 11:337-344.

Lex BW, Ellingboe J, LaRosa K, Teoh SK, Mendelson JH (1993) Platelet adenylate cyclase and monoamine oxidase in women with alcoholism or a family history of alcoholism. Harv Rev Psychiatry 1:229-237.

Li T-K (1995) The Collaborative Study on the Genetics of Alcoholism: Biochemical markers. Alc Hlth Res World 19:234-235.

Menninger JA, Baron AE, Tabakoff B (1998) Effects of abstinence and family history for alcoholism on platelet adenylyl cyclase activity. Alcohol Clin Exp Res 22:1955-1961.

Menninger JA, Tabakoff B (1997) Forskolin-stimulated platelet adenylyl cyclase activity is lower in persons with major depression. Biol Psychiatry $42: 30-38$.

Nagy LE, Diamond I, Gordon A (1988) Cultured lymphocytes from alcoholic subjects have altered cAMP signal transduction. Proc Natl Acad Sci USA 85:6973-6976.

Nakamura K, Iwahishi K, Matsuo Y, Miyatake R, Ishikawa Y, Suwaki H (1996) Characteristics of Japanese alcoholics with the atypical aldehyde dehydrogenase $2 * 2$ : I. A comparison of the genotypes of ALDH2, 
$\mathrm{ADH} 2, \mathrm{ADH} 3$, and cytochrome P-4502E1 between alcoholics and nonalcoholics. Alcohol Clin Exp Res 20:52-55.

Neiswanger K, Kaplan G, Hill SY (1995) Exclusion of linkage between alcoholism and the MNS blood group region on chromosome $4 \mathrm{q}$ in multiplex families. Am J Med Genet 60:72-79.

Nuutinen H, Lindros K, Hekali P, Salaspuro M (1985) Elevated blood acetate as indicator of fast ethanol elimination in chronic alcoholics. Alcohol 2:623-626.

Parsian A, Todd RD, Cloninger CR, Hoffman PL, Ovchinnikova L, Ikeda H, Tabakoff B (1996) Platelete adenylyl cyclase activity in alcoholics and subtypes of alcoholics. Alcohol Clin Exp Res 20:745-751.

Ratsma JE, Gunning WB, Leurs R, Schoffelmeer ANM (1999) Platelet adenylyl cyclase activity as a biochemical trait marker for predisposition to alcoholism. Alcohol Clin Exp Res 23:600-604.

Roine RP, Eriksson CJP, Ylikahri R, Penttila A, Salaspuro M (1989) Methanol as a marker for alcohol abuse. Alcohol Clin Exp Res 13:172175 .

Saito T, Katamura Y, Ozawa H, Hatta S, Takahata N (1994) Platelet GTP-binding protein in long-term abstinent alcoholics with an alcoholic first-degree relative. Biol Psychiatry 36:495-497.

Salomon Y, Londos C, Rodbell M (1974) A highly sensitive adenylate cyclase assay. Anal Biochem 58:541-548.

Schmidt K, Klatt P, Mayer B (1993) Hypercholesterolemia is associated with a reduced response of smooth muscle guanylyl cyclase to nitrovasodilators. Arterioscler Thromb 13:1159-1163.

Schuckit MA, Tsuang JW, Anthenelli RM, Tipp JE, Nurnberger JI Jr (1996) Alcohol challenges in young men from alcoholic pedigrees and control families: A report from the COGA project. J Stud Alcohol 57:368-377.

Seamon K, Daly JW (1981) Activation of adenylate cyclase by the diterpene forskolin does not require the guanine nucleotide regulatory protein. J Biol Chem 256:9799-9801.

Sillanaukee P (1996) Laboratory markers of alcohol abuse. Alcohol Alcohol 31:613-616.

Skiba NP, Hamm HE (1998) How Gs alpha activates adenylyl cyclase. Nat Struct Biol 5:88-92.

Smith PK, Krohn RI, Hermanson GT, Mallia AK, Gartner FH, Provenzano MD, Fujimoto EK, Goeke NM, Olson BJ, Klenk DC (1985) Measurement of protein using bicinchoninic acid. Anal Biochem 150: 76-85. [Published erratum appears in Anal Biochem (1987) 163:279.]
Sobell LC, Sobel MB (1992) Timeline follow-back: A technique for assessing self-reported alcohol consumption, in Measuring Alcohol Consumption: Psychosocial and Biochemical Methods (Litten RZ, Allen JP eds), pp 41-72. Humana Press, Totowa, NJ.

Stibler H (1991) Carbohydrate-deficient transferrin in serum: A new marker of potentially harmful alcohol consumption reviewed. Clin Chem 37:2029-2037.

Stibler H, Borg S, Joustra M (1986) Micro anion exchange chromatography of carbohydrate-deficient transferrin in serum in relation to alcohol consumption (Swedish Patent 8400587-5). Alcohol Clin Exp Res 10: 535-544.

Stibler H, Borg S, Joustra M (1991) A modified method for the assay of carbohydrate-deficient transferrin (CDT) in serum. Alcohol Alcohol Suppl 1:451-454.

Tabakoff B (1996) The WHO/ISBRA study on state and trait markers in alcoholism: Progress report. Alcohol Clin Exp Res 20:243A-247A.

Tabakoff B, Hoffman PL (1998) Adenylyl cyclases and alcohol, in Advances in Second Messenger and Phosphoprotein Research (Cooper DMF ed), pp 173-193. Lippincott-Raven, Philadelphia.

Tabakoff B, Hoffman PL, Lee JM, Saito T, Willard B, De Leon-Jones F (1988) Differences in platelet enzyme activity between alcoholics and nonalcoholics. N Engl J Med 318:134-139.

Tanna VL, Wilson AF, Winokur G, Elston RC (1988) Possible linkage between alcoholism and esterase-D. J Stud Alcohol 49:472-476.

Voltaire A, Beck O, Borg S (1992) Urinary 5-hydroxytryptophol: A possible marker of recent alcohol consumption. Alcohol Clin Exp Res $16: 281-285$

von Knorring A, Hallman J, von Knorring L, Oreland L (1991) Platelet monoamine oxidase activity in type 1 and type 2 alcoholism. Alcohol Alcohol 26:409-416.

Waltman C, Levine MA, McCaul ME, Svikis DS, Wand GS (1993) Enhanced expression of the inhibitory protein Gi2 alpha and decreased activity of adenylyl cyclase in lymphocytes of abstinent alcoholics. Alcohol Clin Exp Res 17:315-320.

Wesner RB, Tanna VL, Palmer PJ, Thompson RJ, Crowe RR, Winokur G (1991) Close linkage of esterase-D to unipolar depression and alcoholism is ruled out in eight pedigrees. J Stud Alcohol 52:609-612. 